\title{
ORIGEM E TRANSFORMAÇÃO DOS NÚCLEOS URBANOS DAS CIDADES DE PRESIDENTE BERNARDES E SANTO ANASTÁCIO
}

\author{
Vinicius Oliveira da Silva, Arlete Maria Francisco \\ Universidade Estadual Paulista - UNESP, presidente Prudente, SP. E-mail: viinisilva6@gmail.com \\ Pesquisa Financiada pela FAPESP Processo 2015/10574-0
}

\begin{abstract}
RESUMO
O transporte ferroviário, até o final do século XX, desempenhou papel importante como indutor do desenvolvimento econômico do país e do processo de urbanização de cidades por onde os trilhos passavam. Na região da Alta Sorocabana, a implantação da Estrada de Ferro Sorocabana deu origem aos núcleos urbanos, a partir das suas estações, e o traçado urbano em formato de tabuleiro de xadrez, um elemento morfológico comum entre elas, estes núcleos configuraram uma paisagem cultural significativa. Partindo do estudo de duas destas cidades, Presidente Bernardes e Santo Anastácio, que apresentam características comuns em sua formação urbana, buscou-se investigar a origem dos núcleos originais e a partir da sistematização das informações tentou-se responder algumas questões: quais os princípios formais orientaram os seus traçados? Quais as semelhanças e diferenças entre o traçado e a configuração dos elementos morfológicos entre as duas cidades? E quais as suas transformações ao longo do tempo?

Palavras-chave: Desenho urbano, Alta Sorocaba, Origem dos Núcleos,
\end{abstract}

\section{ORIGIN AND TRANSFORMATION OF URBAN CENTERS OF PRESIDENTE BERNARDES AND SANTO ANASTÁCIO}

\begin{abstract}
Rail transport by the end of the twentieth century, played an important role as a promoter of economic development of the country and the cities urbanization process where the track went. In the region of Alta Sorocabana, the implementation of Sorocabana Railway gave rise to urban centers, from their stations, and urban layout in checkerboard format, a common morphological element between them, these cores configured a significant cultural landscape. From the study of two of these cities, Presidente Bernardes e Santo Anastácio, that have common characteristics in its urban development, we sought to investigate the origin of the original nucleus and from the systematization of information we tried to answer some questions: what are the formal principles guided your strokes? What are the similarities and differences between the layout and configuration of morphological elements between the two cities? And what their changes over time?
\end{abstract}

Keywords: Urban Design, Alta Sorocabana, Origin of Cores. 


\section{INTRODUÇÃO}

O transporte ferroviário desempenhou um papel muito importante como indutor do progresso econômico do país e como desbravador de territórios desconhecidos, pois viabilizou o escoamento da produção e permitiu que colonizadores se lançassem na ocupação de um extenso território, como foi o caso da Estrada de Ferro Sorocabana (EFS), no estado de São Paulo (FRANCISCO, 2015).

Fundada em 1870, foi um dos principais elementos responsáveis pela ocupação do Oeste Paulista juntamente com a introdução da cultura do café - reflexo da expansão cafeeira. A ferrovia representou um meio de transporte rápido, seguro e barato para a o escoamento da produção cafeeira e também serviu para que os negociantes e compradores de terras conhecessem a região, o que favoreceu a penetração para o interior, a implantação dos loteamentos e a sua ocupação (FRANCISCO, 2013).

Assim, Pierre Monbeig (1984) afirma que a fundação dos núcleos urbanos precedeu de pouco à colocação à venda dos lotes rurais. Para o autor, na Alta Sorocabana, houve um perfeito sincronismo entre expansão cafeeira e ferroviária, quando não uma precedência. $E$, de acordo com Francisco (2015), se as estações surgiram como pontos de apoio ao escoamento da produção e à alimentação das máquinas, os núcleos urbanos surgiram como pontos de apoio para a exploração econômica da região.

Esta pesquisa realizou o estudo de duas cidades que surgiram ao longo da Estrada de Ferro Sorocabana: Santo Anastácio e Presidente Bernardes, a fim de registrar a formação de cada uma, e estabelecer comparações entre ambas.

A cidade como produto social é o resultado de uma maneira de pensar e agir sobre o urbano. A origem destas cidades foi resultado de um processo de colonização e de urbanização deliberado como parte de um negócio acerca da especulação da terra, o que pode ter grande influência nas formas urbanas. Assim, o conhecimento dos traçados que originaram estas cidades pode responder algumas questões: quais os princípios formais orientaram os seus traçados? Quais as características projetuais estiveram envolvidas com a estratégia de comercialização das terras, presente na ocupação da região da Alta Sorocabana? Quais as semelhanças e diferenças entre o traçado e a configuração dos elementos morfológicos entre as duas cidades?

\section{OBJETIVO}

Realizar a análise morfológica das cidades de Santo Anastácio e de Presidente Bernardes e investigar a origem dos seus núcleos urbanos. Como objetivos específicos, identificar as transformações ocorridas nos traçados urbanos e identificar os autores da produção do núcleo urbano que originou as cidades.

\section{METODOLOGIA}

Esta pesquisa se desenvolveu a partir do método de análise morfológica, que a partir de LAMAS (1999), PANERAI (2006) e DEL RIO (1990). A análise morfológica urbana encontra-se como uma peça-chave para a compreensão do espaço urbano-social e suas dinâmicas. Fundando o entendimento de análise urbana no que é discutido por DEL RIO (1990) e LAMAS (1993), de forma a analisar a escala micro e macro do tecido urbano, isto é, entender o crescimento da cidade e seus desdobramentos através dos aspectos morfológicos e visuais (individuais e coletivos) que constituem o território urbanizado, agrega-se elementos importantes ao entendimento de análise urbana, que é, sobretudo, uma disciplina de conhecimento da cidade, que atua desvendando esta pela percepção e interpretação do tecido urbano.

Para tanto, foram utilizados bibliografia disponível acerca das cidades em estudo e da ocupação do Oeste Paulista; documentação disponível no Arquivo Público do Estado, no Instituto 
Geográfico e Cartográfico e no Escritório da Inventariança da Rede Ferroviária Federal SA em São Paulo e trabalho de campo.

\section{RESULTADOS}

A partir do trabalho de campo e das fontes recolhidas do Escritório da Inventariança e do Arquivo público do Estado de SP, foi possível coletar uma documentação iconográfica importante para a reprodução gráfica do primeiro desenho original da cidade, bem como da esplanada que circunda a ferrovia e seus equipamentos, possibilitando então uma tentativa de aproximação do primeiro esboço de cidade ao longo da linha férrea, como ilustrado na Figura 1.

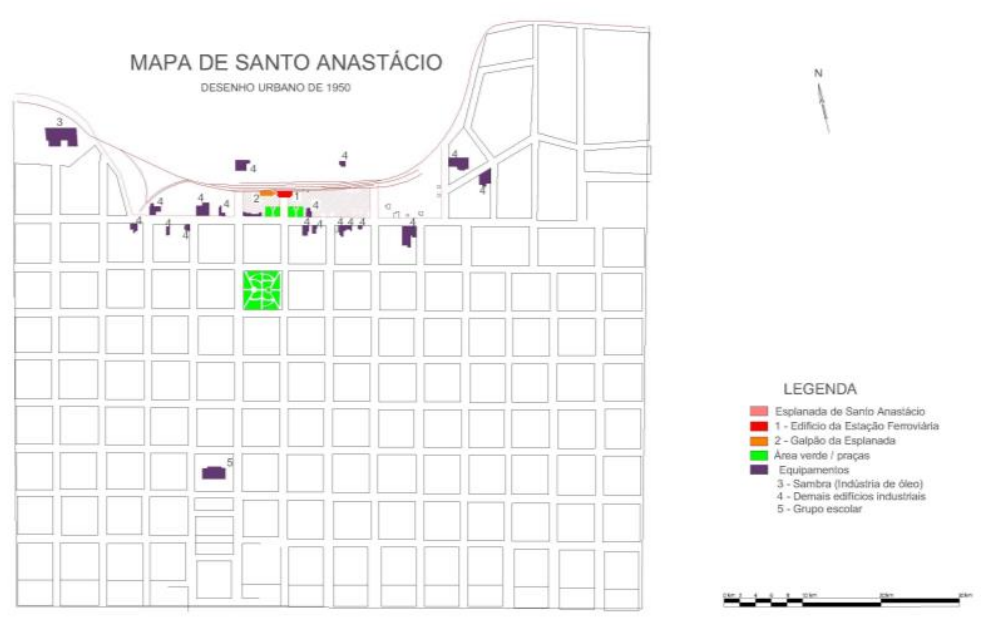

Figura 1. Núcleo urbano original de Santo Anastácio, meados de 1950;

FONTE: Esboço pelo próprio Autor, baseado no acervo do Arquivo Público do Estado de São Paulo

O traçado original de Santo Anastácio foi executado pelo agrimensor Silvano Wendel ${ }^{1}$, entre os anos de 1917 e 1921, que trabalhou na demarcação de terras da Alta Sorocabana, percorrendo grandes glebas que exigiam mapeamento e projetos de urbanização. Nos anos de 1917 a 1919, contratado pela família Ramos, estudou detalhadamente a região de "Guarucaia" (atual Presidente Bernardes) e Santo Anastácio.

Segundo Àvila (1995) o projeto de loteamento de Santo Anastácio foi estabelecido para um desenho de traçado retilíneo, regular e estritamente racional, composto por ruas e avenidas largas, contraponto o traçado urbano das demais cidades criadas na mesma época na Alta Sorocabana. O autor supõe que o agrimensor previu uma urbanização adaptada aos meios de transportes modernos. A respeito do loteamento, segundo o autor, o traçado segue o mesmo padrão estabelecido em Presidente Prudente, ou seja, as quadras possuíam terrenos ou "datas" como chamavam de $44,0 \mathrm{~m} \times 22,0 \mathrm{~m}$ ou $44,0 \times 11,0 \mathrm{~m}$ dependendo da posição onde se localizavam na quadra. A figura 1 demonstra um esquema o qual sugere-se o desenho inicial da cidade, desenho que se assemelha a foto da Figura 2, na qual se verifica a vista aérea da cidade na década de 40. Nota-se, ainda,

\footnotetext{
1 Nascido em 02 de Dezembro de 1890, Silvano Wendel filho de país dinamarqueses nasceu em Buenos Aires, contudo sua família muda-se logo cedo para o Brasil por onde acabam de fixando. Se inspirando na profissão de engenheiro do pai, Wendel ingressa na Escola Politênica de São Paulo, obtendo o diploma de agrimensor. Em 1910, com apenas 20 anos, ele ingressa oficialmente no funcionalismo público, tendo sido admitido como coadjuvante na comissão Geográfica e Geológica do Estado de São Paulo. . AVILA JUNIOR, C. J. Santo Anastácio: Historia de uma Cidade. Santo Anastácio, [s.n.], 1995. P. 31-33.
} 


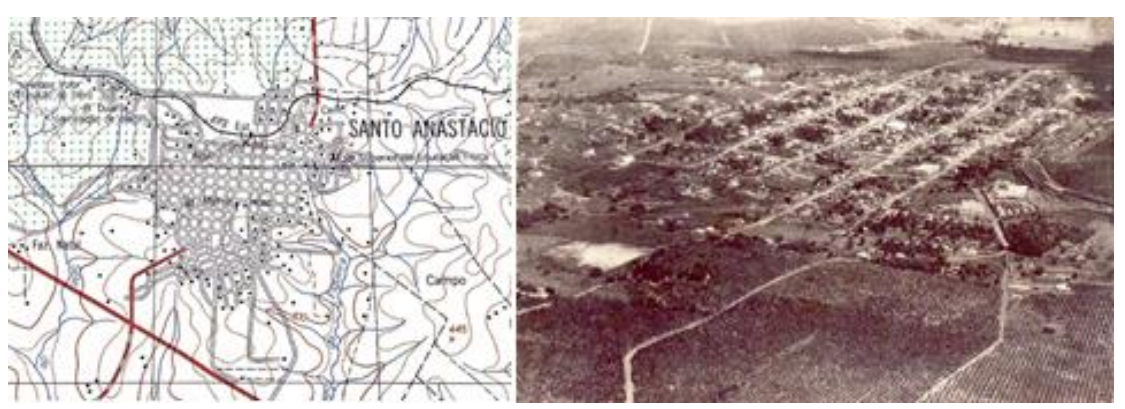

Figura 2. Fotografia aérea do Município de Santo Anastácio;

FONTE: IGC

Figura 3. Mapa Cadastral do Oeste Paulista com o recorte do núcleo urbano de Santo Anastácio, em meados de 1970

FONTE: IBGE
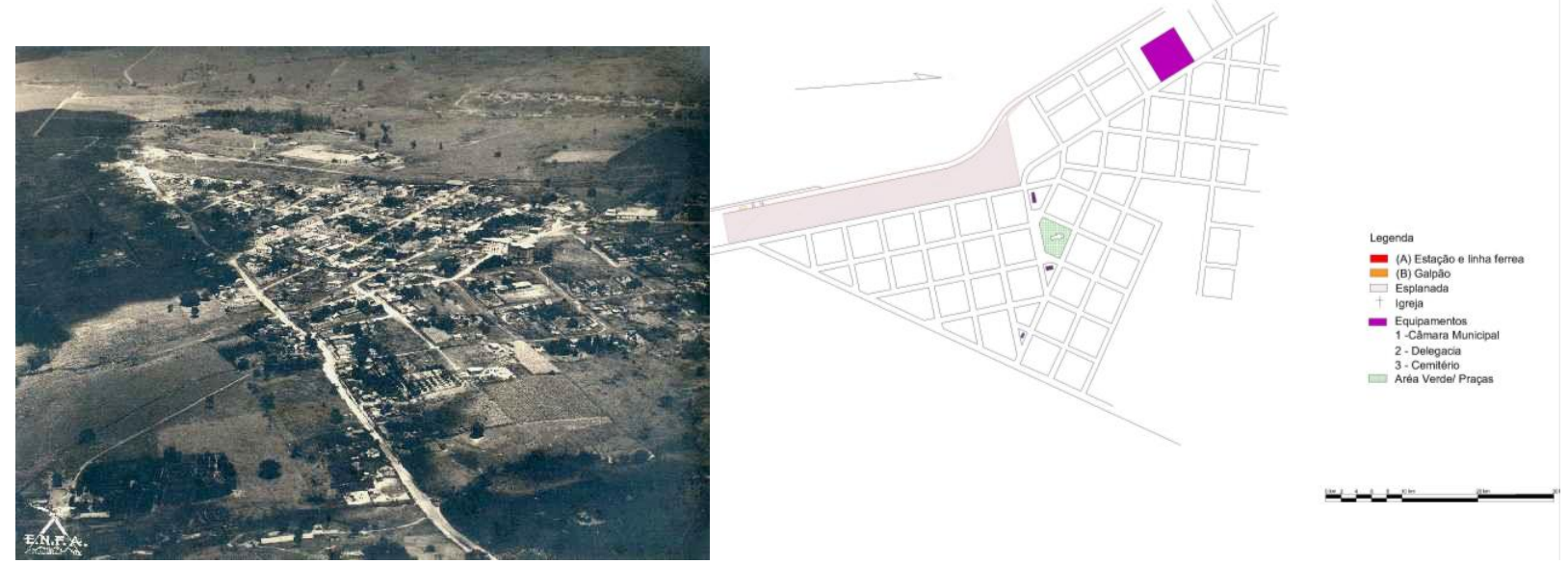

Figura 4. Desenho do núcleo urbano de P. Bernardes

FONTE: Esboço pelo próprio Autor, baseado nos mapas do Arquivo Público do Estado de SP

Figura 5. Fotografia aérea do núcleo urbano de P. Bernardes, ano de 1941

FONTE: IGC

Já o traçado urbano de Presidente Bernardes foi possível ser redesenhado graças aos desenhos fornecidos pelo arquivo público. Por interpretação iconográfica percebe-se que parte do traçado segue a linha do Agrimensor, o mesmo para as duas cidades, do traçado retilíneo e regular. Entretanto, por alguma forma que não foi possível delimitar ainda, algumas quadras foram desenhadas de forma triangular, designando ao desenho urbano da cidade um caráter um tanto quanto diferenciado. A Figura 4 ilustra a reprodução desse núcleo urbano, que muito se assemelha a fotografia área de 1941, da figura 5.

A partir do trabalho in loco e dos desenhos realizados pelo autor, viu-se que além da proximidade física e histórica de formação das duas cidades, no quesito esplanada as duas apresentaram importantes dinâmicas de serviços e relação da estação com o comércio e densidade habitacional. A Figura 6 a qual apresenta uma reprodução das duas esplanadas, ambas reproduzidas na década de 30 , apresenta a semelhança do complexo industrial próximo à ferrovia, pois facilitava o escoamento de mercadoria. A esplanada recebia também a moradia de pessoas ligadas a ferrovia, os trabalhadores ferroviários tinham suas casas próximas às instalações da linha férrea, bem como pessoas ligadas ao comércio promovido pelo grande fluxo ocasionado pela linha. Ambas esplanadas foram executadas e arquitetadas pelo fundador da ferrovia em ambos os casos, João Fairbanks (ÁVILA,1996). 


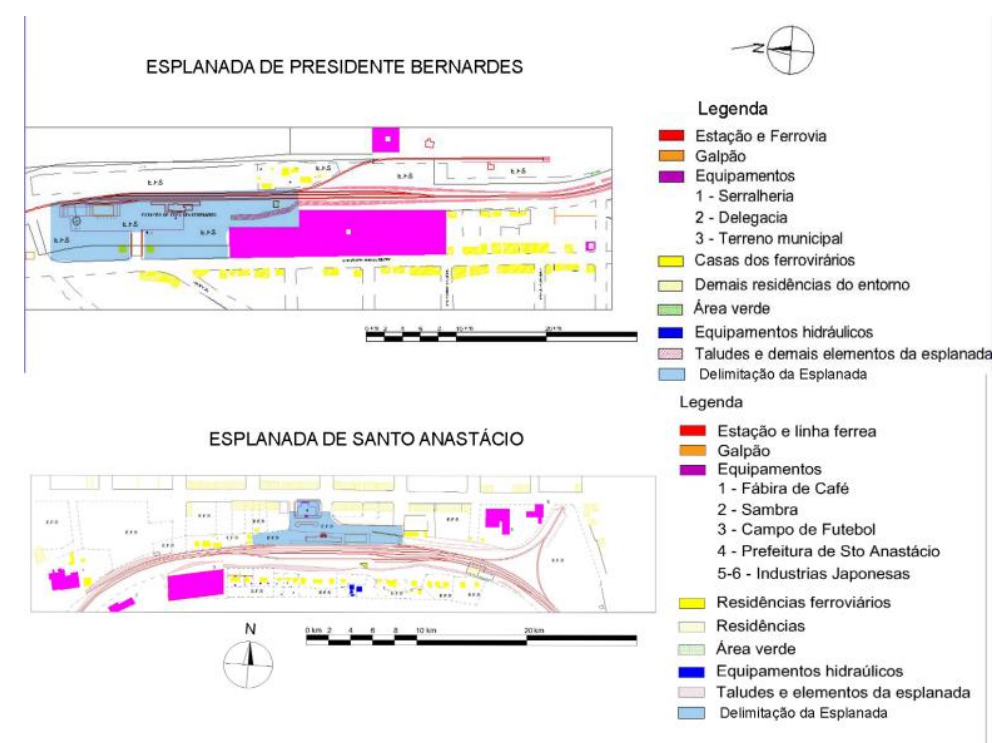

Figura 6. Reprodução gráfica das esplanadas das cidades de P. Bernardes e Sto. Anastácio em meados da década de 40

FONTE: Ilustração do próprio autor baseado no arquivo de mapas do escritório da FEPASA

\section{DISCUSSÕES}

Respondendo às perguntas feitas inicialmente na introdução, ambos traçados das cidades têm forte influência no sistema métrico europeu/francês, das quadras ortogonais e uniformes, entretanto no caso de Presidente Bernardes há algumas quadras em formas triangulares, que podem possuir alguma relação com a topografia da região, entretanto não foi possível levantar essa informação, e sua relação com os dados existentes. Antagonicamente ao caso das cidades coloniais, essas originadas no séc. XIX já vinham perdendo a característica de sua interligação com a igreja. Nas duas cidades, os edifícios concedidos à igreja não pertencem ao eixo econômico e de concentrado fluxo de pessoas, sendo que em Santo Anastácio, segundo o site da Paróquia, esta só foi executada na década de 50 (Figura 7). Antigamente, as pessoas assistiam as missas noutras cidades, contudo há um espaço para a paróquia desde o primeiro desenho em P. Bernardes, todavia com sua construção somente tardiamente também.
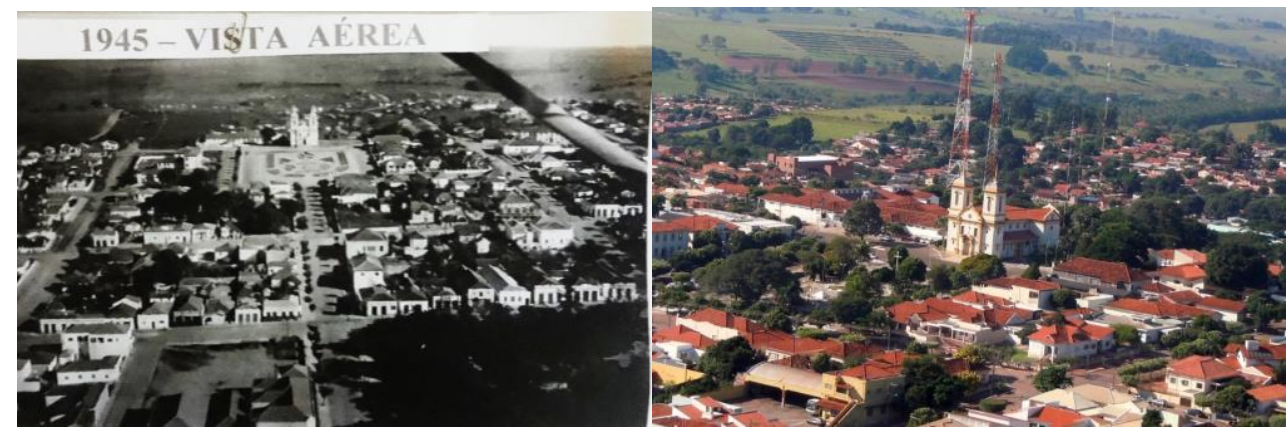

Figura 7. Fotos da Igreja Matriz nas décadas de 50 e anos 2000

Fonte: Biblioteca Municipal de Santo Anastácio

Entretanto a cidade de P. Bernardes não apresentou uma expansão significativa comparada a Santo Anastácio, como ilustrado na Figura 8. Se comparada a Figura 5, anteriormente 
apresentada, a cidade visualmente denota considerável estagnação em relação ao seu crescimento. A Figura 8 abaixo apresenta uma ilustração referente ao crescimento das cidades ao longo dos anos, visto que Anastácio, à esquerda, apresenta considerável crescimento e expansão dado principalmente por adesão de loteamentos recentes tanto de condomínios fechados, bem como para habitação de interesse social. Já a cidade de Presidente Bernardes como visto em figura pouco de alterou em desenho urbano comparado à Anastácio, de acordo com os registros coletados na Prefeitura há poucos registros de loteamentos novos e poucos fundamentos de bairros demonstrando uma falta de interesse
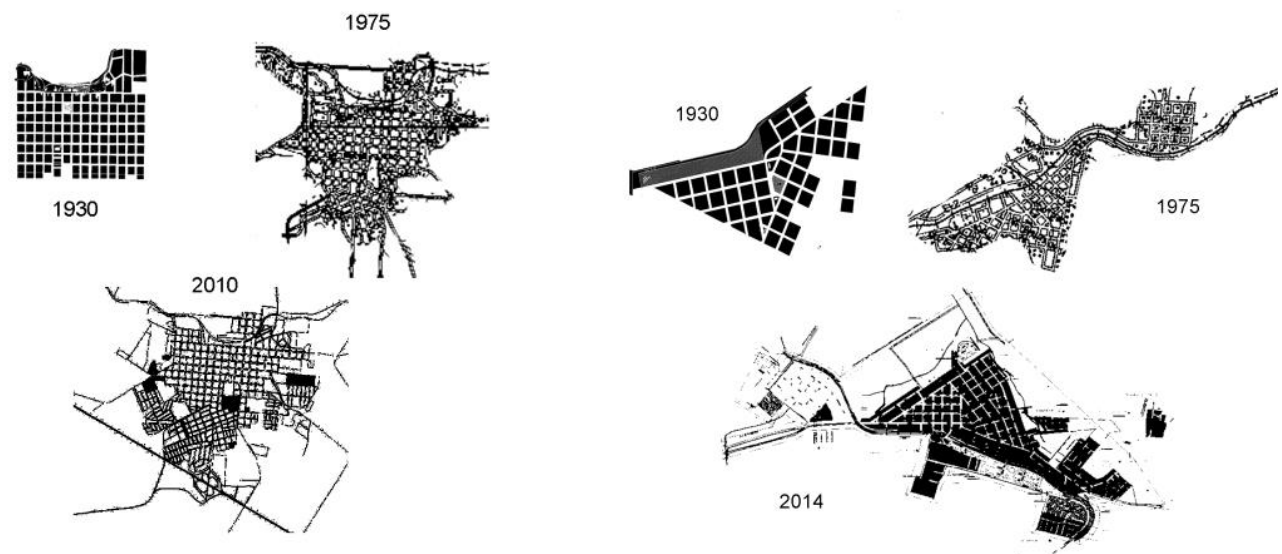

Figura 8. Representação do crescimento dos núcleos urbanos, à esquerda Santo Anastácio, à direita Presidente Bernardes

FONTE: Autor

\section{CONCLUSÃO}

Essa presente pesquisa enuncia a importância do resgate histórico e da memória de nossas cidades, pois pouco tem sido feito quanto à recuperação dos dados históricos e suas relações coma história do urbanismo. Esse recorte de pesquisa visa fomentar essa retomada de memória e reorganizar os dados históricos entrelaçando-os com a história de formação do Oeste Paulista. Ao percursar sobre essas cidades percebe-se uma considerável alteração na paisagem urbana, principalmente na cidade de Sto. Anastácio com o impulsionamento de industrias de médio porte, proporcionando um certo crescimento da cidade. Grande parte do crescimento se deu pela tentativa do poder público em suprir o déficit habitacional do município, tanto que grande parte do crescimento urbano se deu através do espraiamento dos loteamentos urbanos com finalidade de adensamento por habitações de interesse social como também por interesse do mercado imobiliário em loteamentos fechados.

Em Suma, as cidades, por mais que geograficamente próximas, apresentam considerável singularidade no desenvolvimento econômico municipal, motivo o qual não se sabe por precisão, mas acredita-se que grande parte se deu pela administração municipal do Município no decorrer dos anos. As cidades por mais que tenham origem cronológica estreitamente próxima, apresentam singularidades em cultura, desenho urbano, morfologia urbana e costumes diferenciados, confirmando mais uma vez a pluralidade urbana mesmo quando desenhadas para serem semelhantes, as vezes pelo mesmo agrimensor, como no caso das duas em estudo.

\section{REFERÊNCIAS}

AVILA JUNIOR, C. J. Santo Anastácio: História de uma Cidade. Santo Anastácio, [s.n.], 1995.

DEL RIO, V. Introdução ao desenho urbano no processo de planejamento. São Paulo: Pini, 1990. 
FRANCISCO, A. M. A EFS como linha de penetração para a ocupação da Alta Sorocabana In: FIORIN, E.; HIRAO. H. (Orgs.). Cidades do Interior Paulista: Patrimônio Urbano e Arquitetônico.1 ed. Jundiaí: Paco Editorial: Cultura Acadêmica, 2015, v.1, p. 81-106.

LAMAS, J. M. R. G. Morfologia Urbana e Desenho da Cidade. Lisboa: Ed. Fundação Gulbenkian, 1993.

PANERAI, P. Análise urbana. Trad. Francisco Leitão. Brasília: Editora da UNB, 2006. 